\title{
DYNAMIC SOLAR POWERED ROBOT USING DC-DC SEPIC TOPOLOGY
}

\author{
M.Mohanraj ${ }^{1}$, Rani Thottungal ${ }^{2}$, S.Johnson ${ }^{3}$ \\ ${ }^{1}$ Assistant Professor, ${ }^{2}$ Professor and Head, EEE Dept, Kumaraguru College of Technology, Tamil Nadu, India \\ ${ }^{3} P G$ Scholar, Embedded Systems, Kumaraguru College of Technology, Tamil Nadu, India
}

\begin{abstract}
This paper provides an idea to maintain constant voltage to the charging battery at both low and high level light intensity by using SEPIC topology in solar powered robot. Here two batteries are used, one is for charging and another is for discharging. When battery 1 get charged in mean time the battery 2 which is already charged is used to run the robot, Switching will be controlled by ARM processor using DPDT relay, and also voltage and current levels are monitored. Maximum Power Point tracking of solar will be done by single axis tracking system.
\end{abstract}

Keywords: Battery system, Solar MPPT, Robot model, SEPIC topology

\section{INTRODUCTION}

Autonomous robotic vehicle is used in space craft and also in unmanned area where power supply for robot is provided by the minimized and efficient solar cells .Rechargeable batteries are used to store the power and also supplies the robot. When there is no sufficient radiation, the rover has to reduce its power consumption [3]. The Real-Time examples are Sojourner, Zoe, SOLERO. These Robots are used for various applications. Where in these Robots the output from the solar panel is continuously varying accordance with the light intensity and this varying output may create some problems in power quality. So the SEPIC converter employed to have constant magnitude in voltage and current irrespective of solar variation. In this paper we proposed a robotic vehicle model to verify the charger output voltage at wide range of input. It has three sections. Section II gives overview of robotic setup. Section III aims to tack maximum power from solar energy using single axis solar tracking system Section IV provides battery switching and charging system

\section{ROBOT MODEL}

The block diagram of the proposed Robotic vehicle is shown in Fig 2 .The Robot consist of 2 wheel with 2 DC Motor with $30 \mathrm{rpm}$ which is controlled by motor driver circuit. The Robot is powered by Solar Power system with single axis tracking [4].Dual rechargeable batteries are used to store and supply to the Robot. Software part of Robot is divided into three programming part. One part of programing controls solar tracking system. Another part provide PWM signal to charger with SEPIC converter. Other part of programming monitors the voltage and current level battery and solar panel. Complete function of proposed Robot is controlled by LPC2148 ARM 7. Robot functional control is done by the wireless RF remote control. Hardware model of proposed system is given in Fig.1

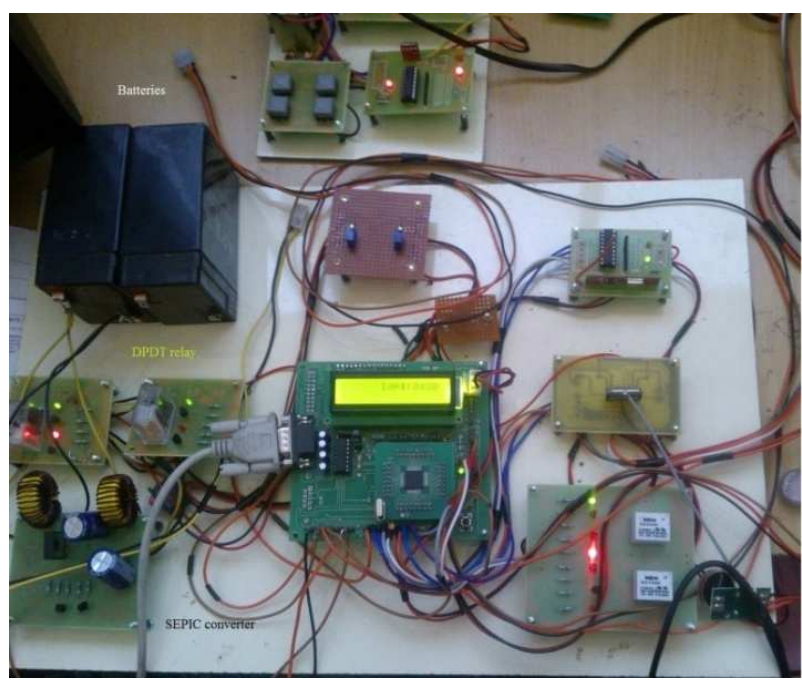

Fig.1 Hardware model of proposed robot model

\section{SOLAR TRACKING SYSTEM}

Supply to the robot mainly depends on the solar energy.Fig.3 shows block diagram of solar tracking system.Fig.4 shows experimental setup of single axis solar tracking system It is necessary to track the maximum power point of solar panel. In this system we use solar panel with following specification based on to our requirement. Maximum Power(Pmax) 5watts ,Tolerance $=10 /-10 \%$, Maximum Power Voltage 12 volts ,Maximum Power Current .71 amps, Open Circuit Voltage (Voc) 10.8 volts, Short Circuit Current (Isc) 0.57amp ,Temp coefficient of Voc $-0.37 \times 102 \mathrm{~A} / \mathrm{C}^{\circ}$ Temp coefficient of ISC $0.08 \times 102 \mathrm{~A} / \mathrm{C}^{\circ} \mathrm{NOC} 47 \mathrm{C}^{\circ}$ Dimensions 12.5 - 7 - 1 (LxWxD - inches) Weight $2.2 \mathrm{lbs}$ solar Cells - 36,Cell Technology Polycrystalline, Power Pmax $/{ }^{\circ} \mathrm{C}-$ minus $0.44 \%$, where 2 LDR (Light Depend Resistor) are used to sense the light Single axis tracking system has proposed here. 


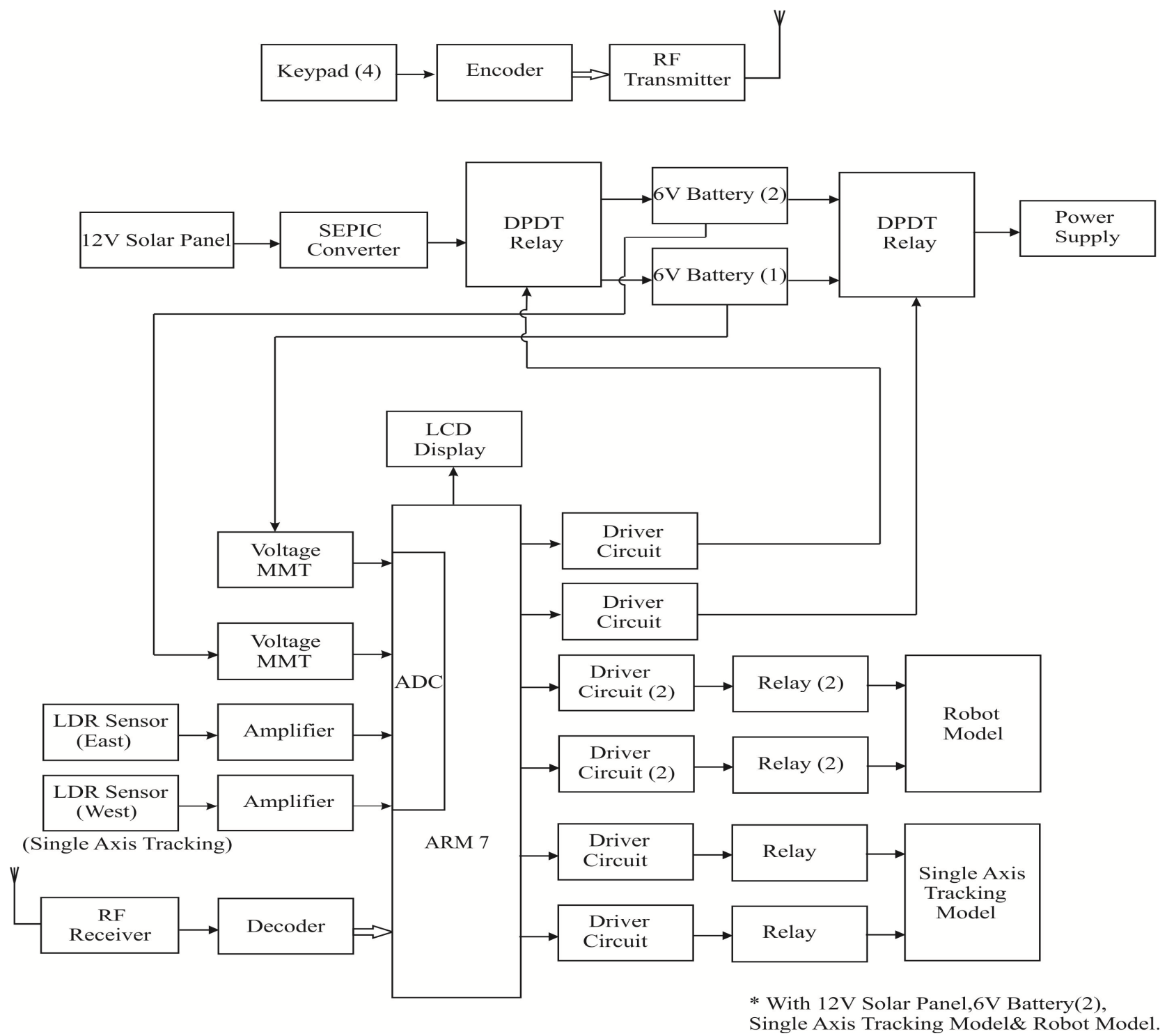

Fig.2 Overview of Robotic system

The tracking system is controlled by the ARM, based on LDR values. In tracking algorithm, $2 \mathrm{LDR}(5.6 \mathrm{Kohm})$ values are compared and based on the value solar panel will be rotate towards the higher LDR value direction. For rotating the solar panel DC motor with 30rpm is used. This DC motor is connected with 32 teeth worm gear, Panel rotation based on worm gear calculation, worm gear calculation consist following parameters, number of teeth on worm wheel, outer diameter of worm wheel, Inner diameter of worm wheel, number of starts on worm, axial pitch of worm, pitch circle diameter of worm, Torque of the motor.

\section{POWER SYSTEM}

\subsection{Battery System}

Battery system consists of 2 batteries, one is for charging and another one is for discharging. In existing system only one battery has been used. Demerit of existing system is that battery will be used to supply only after it get full charged, while charging the battery, system remains ideal . 


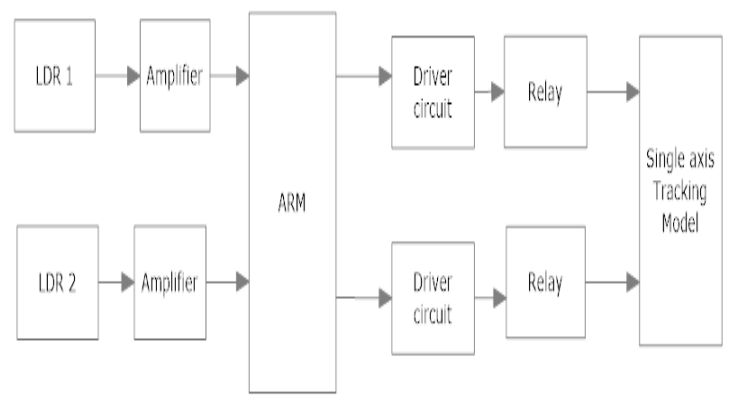

Fig.3 Solar tracking system

2 battery concept is proposed in [1] to overcome the demerit of existing system. Battery system is shown in Fig3 Switching between two batteries is done by host ARM processor, where the voltage level of both batteries is measured by voltage measurement circuits .Measured voltage values are compared in switching algorithm.

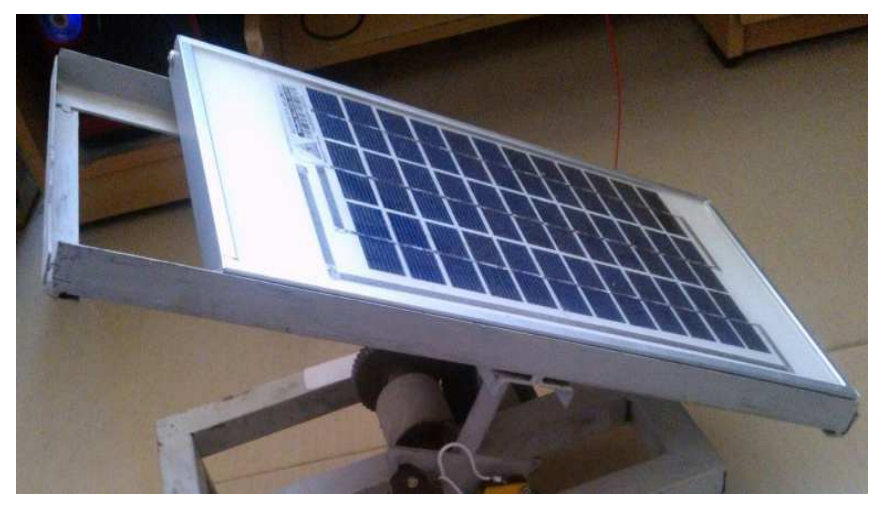

Fig.4 Single axis solar Tracking system

If battery 1 gets high voltage and this will supplies to the Robot, switching will be done by using Double Pole Double Throw switch. Also deadline of voltage level to be measured, if battery 1 reaches its end voltage, switch will disconnect from the Robot. Meanwhile ARM processor is monitored the voltage and current level and these values are displayed in LCD $16 \mathrm{X} 2$

\subsection{Charging System}

The charging system consist of, I/V sensor and SEPIC topology[7],[8] , SEPIC converter is used to maintain constant output voltage from the converter at both low and high level light intensity . I/V sensor used to measure voltage and current at solar panel output, PWM signal to MOSFET is given by
ARM processor based on the $\mathrm{I} / \mathrm{V}$ sensor .Design of SEPIC topology is given below

\subsubsection{SEPIC Topology Design}

Design of SEPIC DC-DC converter is presented in this paper. Hardware design of SEPIC converter is shown in Fig.6. The circuit configuration of the proposed converter is very simple, shown in Fig.5.

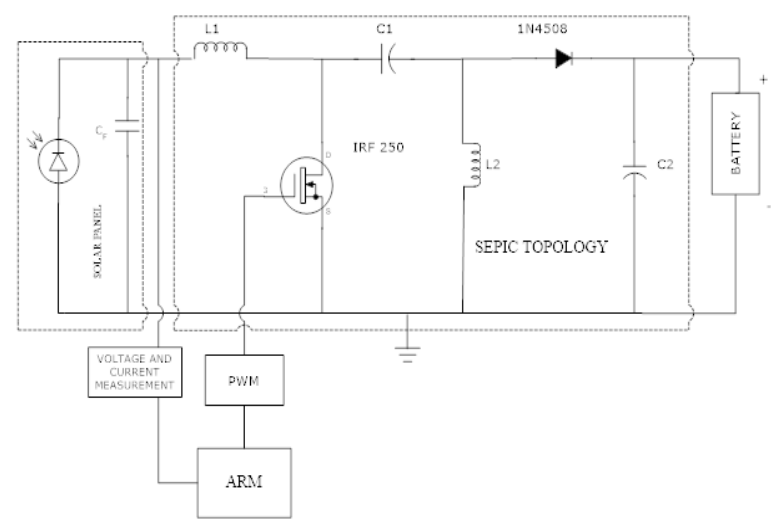

Fig.5. SEPIC Topology

The proposed converter employs a coupled inductor with same number of winding turns in the primary and secondary sides. In SEPIC converter, only one single switch is being used. The input inductor $\mathrm{L} 1$ and switch $\mathrm{S}$ provides continuous input current and performs boost operation. The clamping capacitor $\mathrm{C} 1$ and secondary coupled inductor winding L2 operates as buck or boost operation. The PWM signal will be given by LPC2148ARM based on the I/V sensor value, SEPIC operates at CCM mode. Duty cycle will be calculated by given (1)

$$
D=\frac{V_{\text {oUT }}+V_{d}}{V_{I N}+V_{\text {OUT }}+V_{d}}
$$

Where Vd is voltage drop at diode. Inductor selection is based on ripple current, determining value of inductance is to the allow peak to peak ripple current to be approximately $40 \%$ of maximum input current at the minimum input voltage . Ripple current is given by following equation(2),

$$
\Delta I_{L}=I_{I N} \times 40 \%=I_{I N} \times \frac{V_{O U T}}{V_{I N(\min )}} \times 40 \%
$$

Inductor value is calculated by the following equation (3), 


$$
L_{1}=L_{2}=L=I_{I N} \times \frac{V_{I N(\min )}}{\Delta I_{L} \times f_{S W}} \times D_{\max }
$$

fSW switching frequency, Dmax Duty cycle at minimum Vin .MOSFET selection based on the minimum threshold voltage, the $\mathrm{ON}$ resistance, gate drain-charge and the maximum drain to source voltage and also conduction loss and switching loss should not exceed the package rating. SEPIC capacitor $\mathrm{C} 1$, depends on the RMS current which is given by following equation (4),

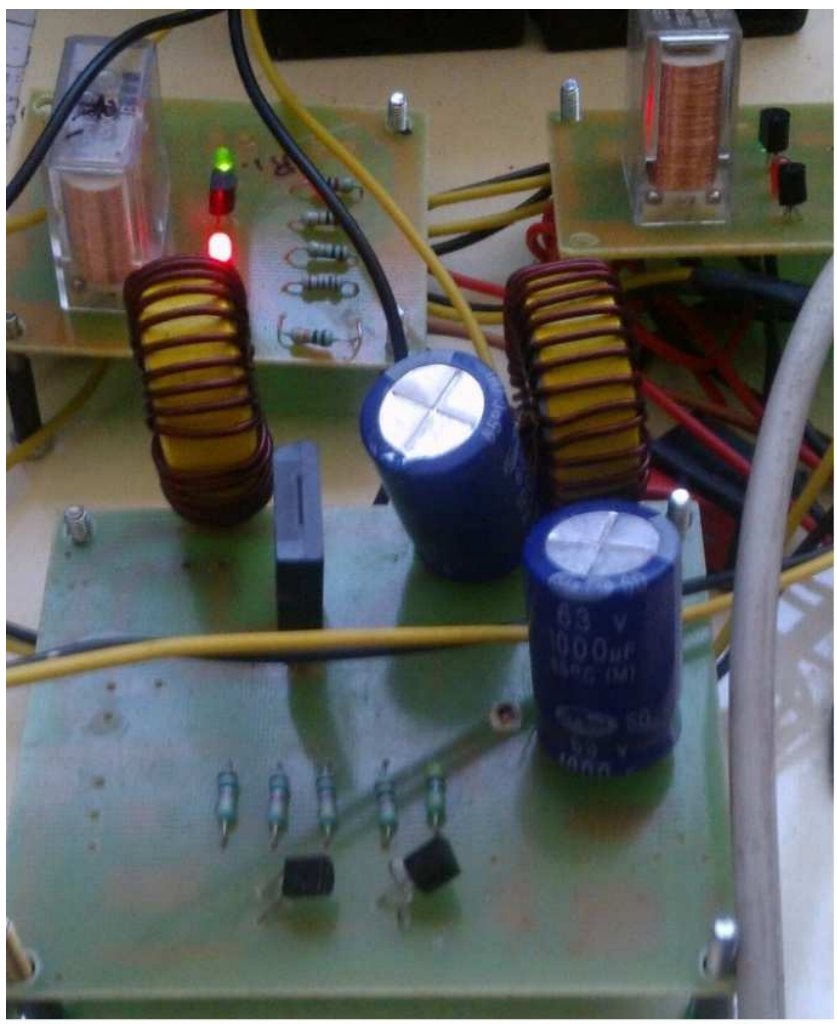

Fig.6. Hardware design of SEPIC

$$
I_{C 1(\mathrm{rms})}=I_{O U T} \times \frac{\sqrt{V_{\text {OUT }}+V_{d}}}{V_{I N(\min )}}
$$

C1 must be rated for large RMS current relative to the output power. Output capacitor C2 must be capable of handling maximum RMS current. Fig shows our required SEPIC converter .Closed loop SEPIC converter is designed for wide input range $3-15 \mathrm{~V}$, output $12 \mathrm{~V}$ at MATLAB Simulink .Fig.7 shows Simulink block of SEPIC converter Simulation result is shown in Fig.8 It shows the output voltage to maintain constant

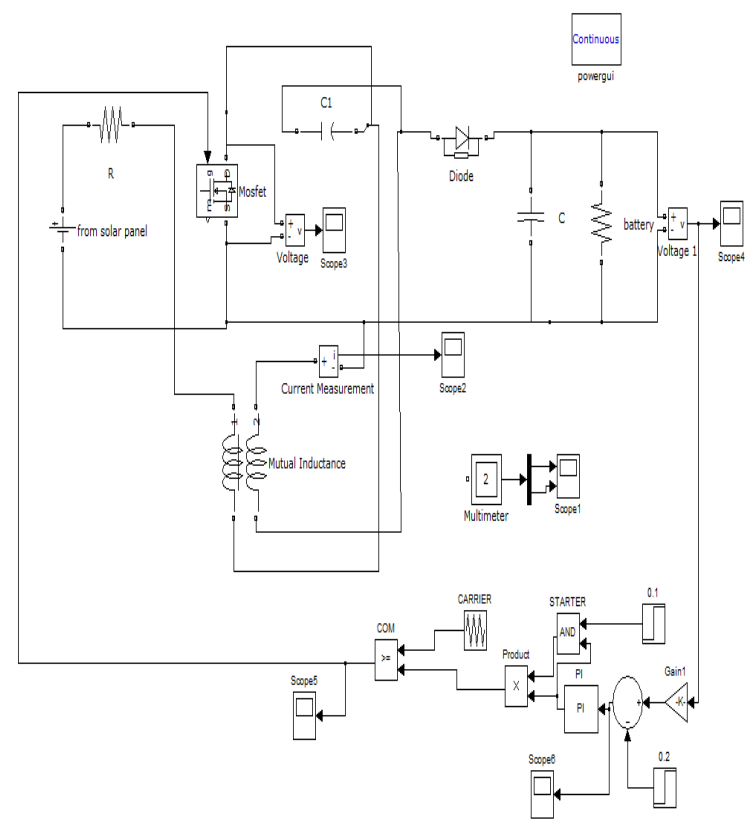

Fig.7. Matlab Simulink Block

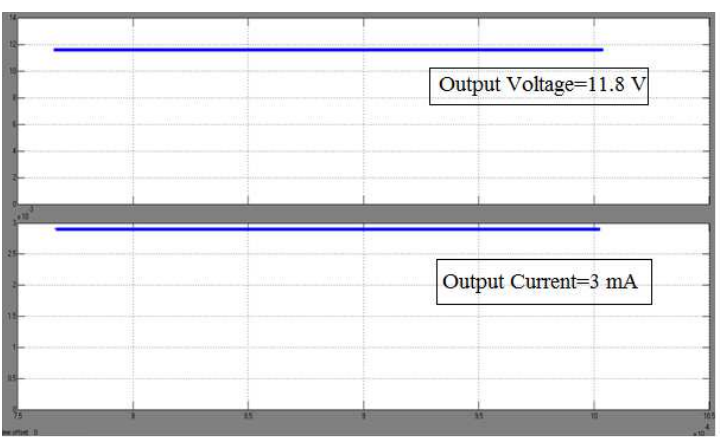

Fig.8. Simulation result

\section{CONCLUSIONS}

Thus the proposed system provides an efficient charging technique for the rechargeable batteries by using SEPIC topology. The constant voltage can be provided to the battery irrespective of the variation in the input voltage from the solar panel .Hence the life time of the battery is improved. Also back up battery concept is to prove a maintainable and commercially feasible solution applied to Robot

\section{REFERENCES}

[1]. Tom'as de J. Mateo Sanguino and Justo E. Gonz'alez Ramos" Smart Host Microcontroller for Optimal BatteryCharging in a Solar-Powered Robotic Vehicle" IEEE/ASME Tractions on Mechatronics, Vol:. 18,pp 1039-1049, 2013 
[2]. H. J. Eisen, L. C. Wen, G. Hickey, and D. F. Braun, "Sojourner mars rover thermal perfomance," presented at the 28th Int. Conf. on Environmental Systems, Danvers, MA, 1998.

[3]. M. Bajracharya, M. W. Maimone, and D. Helmick, "Autonomy for mars rovers: Past, present, and future," Computer, vol. 41, no. 12, pp. 44-50, 2008.

[4]. Y. Takahashi, S. Matsuo, and K. Kawakami, "Hybrid robotic wheelchair with photovoltaic solar cell and fuel cell," in Proc. Int. Conf. Control,Autom. Syst., Seoul, Korea, 2008, pp. 1636-1640.

[5]. J. E. Gonz'alez Ramos, "Battery charging optimization with steerable solar cells," M.S. thesis, Dept. Electron. Eng., Comput. Syst. Autom., Univer-sidad de Huelva, Huelva, Spain, 2010

[6]. N. Smith, "Dynamic power path management simplifies battery charging from solar panels," Texas Instruments, Dallas, TX, Tech. Rep. SLUA394,2006.

[7]. A. Chih-Chiang Hua, B. Cheng-you Tsai "Design of a Wide Input Range DC/DC Converter Based on SEPIC Topology for Fuel Cell Power Conversion" International Power Electronics Conference 2010

[8]. Al-Saffar, M.A. ; Ismail, E.H. ; Sabzali, A.J. ; Fardoun, A.A. " An Impoved opology of SEPIC converter with reduced output ipple voltage" Power Electronics, IEEE Transactions on Vol: 23, pp. 2377 - 2386,

\section{BIOGRAPHIES}

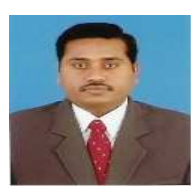

M.Mohanraj, received B.E degree in Electrical and Electronics Engineering from Bharathiar University in the year 2001 and M.E (Power System) from Annamalai University in 2005.Currently he is pursuing Ph.D work under Anna University ,Chennai. He is a senior Assistant Professor of EEE department in Kumaraguru College of Technology, Coimbatore.He is having one year of industrial and 12 years in teaching experience.He haspublished twelve papers in National conferences and five journal.He is a Life member in Indian Society for Technical Education (India). His research area includes Wind Energy Conversion, Solar Energy, Machines and Power Quality issues.

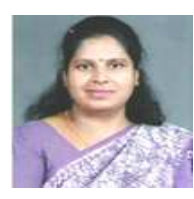

Rani Thottungal, obtained her B.E and M.E degrees from Andhra University and Doctorate from Bharathiar University. She is currently working as Professor and Head in EEE department, Kumaraguru College of Technology, Coimbatore. Her research interest includes Power System, Power Inverter and Power Quality Issues.

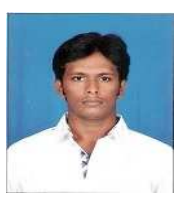

S.Johnson completed his B.E(ECE) in Vel Tech Engineering College 2012 ,Avadi, Chennai and pursuing final year M.E. in Embedded System in Kumaraguru College of Technology, Coimbatore. 